ErIKson, D. (1952). J. gen. Microbiol. 6, 286-294.

\title{
Temperature/Growth Relationships of a Thermophilic Actinomycete, Micromonospora vulgaris
}

\author{
BY DAGNY ERIKSON \\ Bacteriology Department, Foresterhill, University of Aberdeen
}

\begin{abstract}
SUMMARY: The only thermophilic actinomycetes found in composts made from lawn cuttings were members of the genus Micromonospora. The isolates obtained agreed in the main with the description of $M$. vulgaris (Tsiklinsky) Waksman, Umbreit \& Cordon. Three strains have been studied in detail. They are true thermophiles, with an optimum range of growth $45-60^{\circ}$, and appear in abundance at the high-temperature phase of the compost, with a profuse production of aerial mycelium and spores. Spore germination is induced by heat activation, $5 \mathrm{~min}$. at $85^{\circ}$ securing growth under suboptimal conditions. Thin suspensions of spores in $1 \%$ sucrose or in very dilute nutrient broth withstand $100^{\circ}$ for periods of up to $45 \mathrm{~min}$. Only very dense aqueous or saline suspensions are tolerant of these exposures. Surface growth on cellophan bearing a high density of aerial mycelium and spores withstands dry heating at $100^{\circ}$ for $150 \mathrm{~min}$. or at $106^{\circ}$ for $5 \mathrm{~min}$.
\end{abstract}

In an extensive study of $\mathbf{4 8 0}$ cultures of thermophilic and thermoduric microorganisms isolated from the dust, grain, hay, etc., as well as from the milk obtained on various dairy farms, Prickett (1928) found that the only true thermophiles were either spore-forming bacilli or actinomycetes. Gordon \& Smith (1949), making a taxonomic survey of 216 presumed thermophiles collected from many sources, were able to reduce the sporing bacilli to two main species, Bacillus coagulans and $\boldsymbol{B}$. stearothermophilus. The thermophilic actinomycetes have not yet been studied extensively, but from the accounts so far published it would seem that the forms occurring in grass composts belong predominantly to the genus Micromonospora. Tsiklinsky (1899) isolated an actinomyces-like thermophile from decaying straw, manure, etc. which she termed Thermoactinomyces vulgaris, and which was renamed Micromonospora vulgaris by Waksman, Umbreit \& Cordon (1939) as the result of finding similar forms on contact slides in dunged composts. Schütze (1908) was the first to describe in detail the development of a thermophilic actinomycete occurring in spontaneously heated clover hay, which he named Actinomyces monosporus, and which from his pictures is clearly a species of Micromonospora. In their study of the decomposition of the protein and hemicellulose fractions in grass composts, Forsyth \& Webley (1948) noted that the extensive chalk-white encrustation of the upper layers of the compost during the high-temperature phase was attributable to the growth of a species of Micromonospora.

The present study deals with the thermophilic actinomycete flora obtained from a series of grass composts put up during two seasons in Webley's (1947) composting container, and in collaboration with Dr Webley. All isolates are micromonosporae, have marked features in common, and, apart from a broader temperature range and lack of growth on potato, agree in the main with the description of $M$. vulgaris. 


\section{RESULTS}

\section{Growth of micromonospora on compost fibres}

The visible efflorescence on the fibres during the high-temperature phase can easily be seen by microscopical examination to be due to the aerial hyphae produced by the micromonospora; single, lateral spores can be found in all stages of development along the hyphae, and also occasionally in Botrytis-like clusters. It is of interest to note that only the thermophilic micromonosporae produce an aerial mycelium; the mesophilic species are either devoid of aerial growth or produce at most a few sparse branches (Jensen, 1930). The mode of sporulation of $\boldsymbol{M}$. vulgaris will be discussed elsewhere. In practice, the production of an aerial mycelium is an identifying aid in the preparation of enrichment cultures of the organism, which is difficult to isolate except by such means. The conventional dilution methods are seldom successful.

The vegetative filaments are closely attached to the compost fibres and fragments of leaves (Pl. 1, fig. 3), and withstand considerable mechanical shaking without being dislodged. All attempts to isolate the organism on various cellulose media failed, and it seems that the attachment to the fibres and to strips of filter-paper results mainly from the necessity of a support, for the delicate growth, and of aeration for the production of aerial hyphae. It is significant that the micromonosporae appear only in the upper $6 \mathrm{in}$. layer of the compost.

Technique of isolation. Successful isolations have been made by each of the following procedures:

(1) Small portions of compost showing visible encrustation are distributed in small screw-capped bottles containing $10 \mathrm{ml}$. of starch Czapek liquid medium, $\mathrm{pH} \mathbf{7 \cdot 2}$.

(2) The compost is distributed in sterile Petri dishes, and roughly flattened down with disks of sterile filter-paper moistened with starch Czapek solution or mannitol yeast extract.

(3) Small portions of compost are placed on sterile cellophan disks over sterilized compost in Petri dishes, and the whole moistened with mannitol Bacto-tryptone solution.

Incubation is at $60^{\circ}$, and when the typical dry white surface growth appears on the paper after 1-3 days or longer, the organism is purified by plating. The best results were obtained using nutrient (proteose peptone Lab Lemco) agar to which were added $5 \%$ tryptic digest of casein, $0.5 \%$ pea extract, and $1 \%$ soluble starch, $\mathrm{pH} \mathbf{7 \cdot 2}$ (CPS medium).

High-temperature phase of compost. Table 1 is representative of the results obtained during an August sampling. After the high-temperature stage, fungi and thermoduric eubacteria over-ran the darkened compost, and the temperature continued to decline. A sample taken 14 days later, when the temperature had dropped to $25^{\circ}$, yielded growth after 6 days' incubation at $60^{\circ}$ in an enrichment medium. It is clear that the micromonosporae flourish at the peak of the high-temperature phase, which coincides with the most favourable reaction, $\mathrm{pH} 6 \cdot 8-7 \cdot 0$. 
Table 1. Isolation of Micromonospora vulgaris from compost of varying temperatures

Compost

$\begin{array}{cccccc}\begin{array}{c}\text { Day } \\ \text { sampled }\end{array} & \begin{array}{c}\text { Temperature } \\ \left({ }^{\circ}\right)\end{array} & \begin{array}{c}\text { Depth } \\ \text { sampled } \\ \text { (in.) }\end{array} & \begin{array}{c}\text { Moisture } \\ \text { content } \\ (\%)\end{array} & \text { pH } & \begin{array}{c}\text { First appearance } \\ \text { of growth at } 60^{\circ} \\ \text { (days) }\end{array} \\ 1 & 15 & \text { Top } & 89 & 4 \cdot 2 & 7 \\ 2 & 29 & 1-3 & & 5 \cdot 0 & 7 \\ 3 & 50-65 & 3-6 & 63 & 6 \cdot 2 & 6 \\ 4 & 51-65 & 2-6 & & 6 \cdot 8 & 2 \\ 5 & 46-64 & 2-6 & 83 & 6 \cdot 8 & 1 \\ 6 & 50-55 & 3-6 & 75 & 7 \cdot 0 & 2\end{array}$

Growth at different temperatures. Growth does not take place on any medium at $62-80^{\circ}$ or at $30^{\circ}$; it is best at $45-60^{\circ}$, and slight to fair at $37^{\circ}$, depending on humidity, aeration, nature of the inoculum and the medium. The organism is, therefore, a eurithermal thermophile in the sense of Imsenecki \& Solnceva (1945) and of Gaughran (1947), although it would be regarded as an obligate or stenothermal thermophile by Bergey (1919) and by Gyllenberg (1951). Tsiklinsky recorded $42^{\circ}$ as the temperature minimum for growth, but did not state whether for liquid or solid media. In my experience, Murray's (1944) stress on the importance of a water-saturated environment for the production of surface growth of thermophiles on solid media is fully justified. Thus, incubation at $37^{\circ}$ may fail in all cases except in shallow layers of liquid media in stoppered vessels, or in poured plates maintained in a moist chamber. Growth at $37^{\circ}$ is atypical, almost devoid of aerial mycelium, and frequently non-viable. At $50-60^{\circ}$ colonies typically covered with white aerial mycelium are produced in 18-24 $\mathrm{hr}$. in a moist chamber, and may continue to grow for 1-2 days (Pl. 1, fig. 2). But if, after $24 \mathrm{hr}$. at $60^{\circ}$, a thinly sown plate is placed at $37^{\circ}$, growth may continue for at least a week, resulting in giant colonies with successive rings of aerial mycelium (Pl. 1, fig. 1). This mode of growth is comparable to that of mesophilic streptomycetes and fungi, but not to that of mesophilic micromonosporae (Erikson, 1949). The aerial mycelium of $M$. vulgaris stains with Sudan black and Sudan red IV, using the methods of Erikson (1947).

For the production of aerial mycelium and abundant sporulation, soluble starch $(1 \%)$ proved the best addition. The organism is not a marked carbohydrate fermenter, but is characterized by its proteolytic activities. Peptone $(1 \%)$, Bacto-tryptone $(0.1 \%)$, and a tryptic digest of casein $(5 \%)$ are suitable sources of nitrogen. Nitrate nitrogen does not support growth. Casein digest alone often induces autolysis, and, as Forsyth \& Webley (1948) have reported, the continuous use of ordinary nutrient (peptone Lab Lemco) agar at $60^{\circ}$ may inhibit sporulation. The organism will grow at $55^{\circ}$ in a Czapek salt solution containing $1 \%$ soluble starch, $1 \%$ acid hydrolysate of casein (vitamin-free), plus $0.01 \%$ autolysed yeast extract. For maximum growth and rapid recovery after heat treatment, the CPS medium has been used throughout, unless otherwise stated. The $\mathrm{pH}$ of all media was $\mathbf{7 \cdot 2}$. 


\section{Heat activation of spores}

Curran \& Evans (1945) demonstrated the stimulating effect of 'heat shocking' upon the germinative capacities of different bacterial spores, and also upon their ability to grow, when germinated, under suboptimal conditions. The three strains of $\boldsymbol{M}$. vulgaris which have been studied in detail are all responsive to such treatment. Thus $5 \mathrm{~min}$. at $75^{\circ}, 85^{\circ}$ or $90^{\circ}$ will induce growth in $18 \mathrm{hr}$. at $60^{\circ}$ in cotton-wool plugged small tubes of less rich media, which unheated fail to produce growth within the same period-e.g. 4, 3, 2, and $1 \%$ casein digest-Czapek salts liquid media containing $1 \%$ sucrose and $0.01 \%$ autolysed yeast extract. Similarly, the procedure of pre-heating a $250 \mathrm{ml}$. flask containing $150 \mathrm{ml} .1 \%$ maltose $+5 \%$ casein digest Czapek salts medium to $60^{\circ}$ and the inoculum to $85^{\circ}$ for $10 \mathrm{~min}$., rapidly sowing the flask, shaking it at $\mathbf{3 3}^{\circ}$ for $30 \mathrm{~min}$., and then immediately incubating at $60^{\circ}$ gives a more or less coherent surface growth with abundant aerial mycelium in $18 \mathrm{hr}$.; whereas unheated control flasks, sown with unheated inoculum from the same source, and shaken at room temperature, yield, as a rule, poor bottom vegetative growth only.

After $15 \mathrm{~min}$. at $85^{\circ}$ the vegetative mycelium appears to be killed, while the spores for the most part continue to stain well with Gray's spore stain. These spores are not acid-fast. This method, so widely used with other organisms for obtaining an inoculum consisting of spores, has been adopted as a routine.

Preparation of spore suspensions. As with all actinomycetes producing a non-wetting aerial mycelium, considerable difficulty may be experienced in obtaining smooth suspensions. The spores of this organism seem more susceptible to the action of wetting agents than those of mesophilic streptomycetes, and so far one which is non-toxic in effective concentration has not been found. Repeated centrifuging and straining off the flecks of material will ensure a fairly homogeneous suspension, but, if too prolonged, viability is impaired. Filtration by means of positive pressure through three to five layers of sterile filter-paper is less injurious, but wasteful of material. The growth obtained on cellophan placed over the solid medium (Erikson, 1947) has a lower proportion of vegetative to aerial mycelium, and therefore fragments more readily and is more easily suspended after the initial heating than that washed from an agar plate; it is also much more economical of material. The method finally employed was to take the growth on a half-inch cellophan square, rub it off with $5 \mathrm{ml}$. of the suspending fluid into a centrifuge tube, spin to obtain a fairly even dense suspension, heat at $85^{\circ}$ for $15 \mathrm{~min}$., and then dilute, filtering if necessary, so as to yield a suspension containing approximately $15-30 \times 10^{3}$ viable cells $/ \mathrm{ml}$.

The growth on cellophan, when stored at $2^{\circ}$ in a sterile stoppered bottle, retains its vitality for periods up to 6 months. Agar cultures, kept in the refrigerator, may die within a week, although they may remain viable for 1-3 months in stoppered vessels at room temperature. The stock material was kept on cellophan at $2^{\circ}$.

Technique of heat testing. Schütze was disinclined to identify his thermo- 
philic micromonospora with that of Tsiklinsky because his organism withstood $100^{\circ}$ for only $5 \mathrm{~min}$., whereas hers resisted for $20 \mathrm{~min}$. In an analysis of the results of the earlier workers on thermobiosis, Hampil (1932) showed very clearly that the degree of thermal resistance depended largely on the experimental methods. Preliminary experiments with unwashed fragments of a surface pellicle of strain $M$ from an 8-day liquid culture, which was not centrifuged, showed that a few spores survived $30 \mathrm{~min}$. boiling in distilled water in cotton-wool plugged tubes. But when thin aqueous spore suspensions of all three strains, prepared as described above, were heated for varying periods at $100^{\circ}$ in sealed capillaries according to the technique of Morrison \& Tanner (1924), no survivals were obtained. In all experiments, therefore, heating was carried out in sealed capillaries, which were completely immersed in the water-bath.

Effect of suspending fluid upon heat resistance. The work of Robertson (1927) on the effect of osmotic pressure on heat resistance emphasized the protective action of nutrient broth and of sucrose solutions of varying concentrations upon the bacterial cells. This is very marked in the case of the micromonospora spores, which, when adequately dispersed in thin aqueous or saline suspensions, are unable to withstand even $85^{\circ}$ for $15 \mathrm{~min}$.

In a series of experiments designed to discover the longevity of the spore suspensions after this preliminary heating, it was found that when aqueous and saline washings were made from growth on an agar plate, centrifuged once, diluted, heated, and plated immediately, only 4-6\% survived. If the suspensions were placed at $2^{\circ}$ after heating, 98-100\% of the spores died within $24 \mathrm{hr}$. Only in very dense suspensions (containing 500-1000 times as many cells as the former) were 1-2 \% survivals found after storage at $2^{\circ}$ for 6 days. When the experiments were repeated with the surface growth on cellophan strips, which contained a very much lower proportion of diffusible nutrients to be carried over into the suspensions, no survivals were obtained in aqueous or saline suspensions.

Table 2. Effect of heating broth suspensions of Micromonospora vulgaris for $15 \mathrm{~min}$. at different temperatures

$\begin{array}{lccccccccc}\text { Temperature }\left({ }^{\circ}\right) & \ldots & 60 & 65 & 70 & 75 & 80 & 85 & 90 & 95 \\ \text { Viable cells } / \mathrm{ml} . & \ldots & 21,000 & 15,500 & 15,000 & 19,000 & 18,000 & 26,000 & 16,000 & 4000\end{array}$

Table 2 shows the protective effect of nutrient broth, diluted 100 times, as the suspending medium. These figures represent the average of six experiments. The colony count rests on the assumption that each colony is derived from a single spore. Frequent examination of slide cultures has shown that this may not always be true; two or three spores may be seen attached to a fragment of mycelium in the most dilute suspensions; and two or three may be capable of simultaneous germination. Such counts can therefore be taken only as approximate.

Similar values were obtained with $1 \%$ sucrose as the suspending fluid; higher concentrations of the sugar were not as effective. These dilute broth 
and sucrose suspensions could be stored at $2^{\circ}$ for $24 \mathrm{hr}$. without appreciable loss of viability; more prolonged storage resulted in loss. When such suspensions are plated inmediately after heating, the stimulating effect of a short period at $85^{\circ}$ is discernible. This is more noticeable at $5 \mathrm{~min}$. than after $15 \mathrm{~min}$. and is generally lost when the suspensions are allowed to stand, even in the cold. The spores of $1-7$ day cultures grown at $60^{\circ}$ behaved in the same way. After 8-15 days the property of heat-resistance declines together with that of viability. No significant differences were found between the three strains.

Thermal death point. For these tests the dilute broth or sucrose suspensions of spores, prepared as described, were placed directly in ice after the preliminary heating at $85^{\circ}$. They were then distributed on $0.2 \mathrm{ml}$. quantities in capillary tubes, sealed, and immersed in a water-bath at $100^{\circ}$ for varying periods of time. When taken out of the water-bath they were plunged into ice, and left there for approximately $1 \mathrm{hr}$. until all were ready to be plated. The maximum period of resistance to $100^{\circ}$ was 45 min., while $30-35 \mathrm{~min}$. was the more usual end-point. Because of the frequent inhomogeneity of the suspensions, even when prepared in exactly the same manner, the experiments were continued on an average three times weekly over a period of 4 months. Table 3 is representative of the results obtained.

Table 3. Effect of heating sucrose suspensions of Micromonospora vulgaris at $100^{\circ}$ for varying periods

$\begin{array}{lccccccccc}\text { Time heated (min.) } & \ldots & 0 & 5 & 10 & 15 & 20 & 25 & 30 & 35 \\ \text { Viable cells } / \mathrm{ml} . & \ldots & 17,200 & 6000 & 2200 & 400 & 200 & 100 & 100 & 0\end{array}$

Little difference could be found in the heat resistance of spores of 1-7 day growths, or in that of the spores obtained from 2-day cellophan growths kept at $2^{\circ}$ for periods varying from 1 day to 3 months.

Resistance to dry heat. When small strips of the stock growth on cellophan were placed directly into dry capillaries, sealed, and heated in the water-bath, the maximum period for survival at $100^{\circ}$ was found to be $150 \mathrm{~min}$. Similar strips in sealed capillaries were then autoclaved, and proved capable of withstanding $5 \mathrm{lb} . / \mathrm{sq}$. in. pressure $\left(106^{\circ}\right)$ for $5 \mathrm{~min}$. Duplicate sets of suspensions were prepared from the dry-heated growth, and one set of poured plates incubated at $60^{\circ}$ as usual, the other set at $37^{\circ}$. There was little difference in the ratio of survivals at the two temperatures, but the colonies developing at $60^{\circ}$ were regularly covered with aerial mycelium, while those grown at $37^{\circ}$ had very little.

\section{Effect of heat treatment}

On the whole, the growth obtained in all heat-testing experiments has shown remarkable uniformity, being indistinguishable from the stock unheated controls, and showing no loss in vigour or viability. Unheated material was used as the starting-point in all the experiments previously described. When continued subcultures were made from typical colonies derived from heat-treated spores, no progressive enhancement of resistance was obtained. 
Occasionally, in about $1 \%$ of these colonies, there were sectors devoid of aerial mycelium. Subcultures from these sectors grew poorly without aerial mycelium, and died within three generations.

Heat resistance of spores attached to substratum mycelium. When the surface growth is scraped and washed off an agar plate or slope, there still remains growing into the medium the major part of the cells of the colonies, i.e. the substratum or vegetative mycelium with its zonate development of lateral spores, which is comparable with the complete growth of a mesophilic micromonospora (Erikson, 1941). Such washed slopes, flooded with $10 \mathrm{ml}$. saline, were found to withstand the 1-5 min. heating at $100^{\circ}$ required to melt the agar and so yield a liquid suspension, which could be diluted for plating purposes. As the cells cannot be separated from the agar, it is impossible to estimate how far this degree of resistance is due to the protective effect of the colloidal material in suspension.

Stationary liquid cultures are slow to produce bottom vegetative growth (5-7 days), and by then it is usually non-viable, even though on microscopical examination spores may be seen. Unheated liquid cultures shaken at $33^{\circ}$ for 1-3 hr. and then incubated at $60^{\circ}$ may produce a coherent puffball growth of vegetative mycelium with a sparse development of single spores within $18 \mathrm{hr}$. None of this material has shown the degree of heat resistance exhibited by the typical surface growth with abundant aerial mycelium and spores.

\section{DISCUSSION}

The disparity between the visible abundance of micromonosporae in the hot compost and the infrequency with which they appear on dilution plates has been remarked by Waksman et al. (1939) and also by Forsyth \& Webley (1948). In the present work it has been shown that, if several suitable enrichment methods are adopted, the growth of the organism can constantly be demonstrated although its purification may be a time-consuming matter. It is more readily obtained, because present in larger numbers, in the high-temperature phase, but it can also be isolated when the white efflorescence is no longer visible; e.g. 14 days later, when the temperature has dropped to $25^{\circ}$. Grass cuttings taken in winter (January), and incubated in an enrichment medium at $60^{\circ}$ for 18 days have also yielded the same organism.

From the experiments made with aerial growth on cellophan stored at $2^{\circ}$, it is clear that the surface mycelium bearing an abundance of spores is capable of retaining viability and heat-resistant properties for periods up to 6 months. There seems no difficulty, therefore, in postulating that it is by means of its spores that the organism survives outdoors during long periods of tempera tures unfavourable for growth.

What is remarkable is the ability of a small proportion of the spores to withstand such prolonged high temperatures as $45 \mathrm{~min}$. at $100^{\circ}$ in a dilute sucrose or peptone solution, or $150 \mathrm{~min}$. at $100^{\circ}$ when the entire growth is adherent to strips of cellophan simulating compost fibres. Such powers of heat resistance bring the non-acid-fast micromonospora spores in line with certain eubacterial endospores. It is significant that there has been shown a correlation between 
an abundance of lipid-staining aerial mycelium on the one hand, and vigorous growth at $60^{\circ}$ with the production of heat-resistant spores on the other.

This work has been done by the author as a member of the scientific staff of the Agricultural Research Council.

I wish to thank Prof. J. Cruickshank, C.B.E., for the hospitality of his department, and for many interesting discussions on the subject. I am deeply indebted to Dr D. M. Webley for much generous assistance. I also wish to thank Miss Irene Taylor for taking the photographs, Miss Mildred Mackay for invaluable technical assistance, and Dr J. W. Porteous for the $\mathrm{pH}$ and moisture content estimations. Grateful acknowledgement is made to the Agricultural Research Council for an expenses grant.

\section{REFERENCES}

Bergey, D. H. (1919). Thermophilic bacteria. J. Bact. 4, 301.

Curran, H. R. \& Evans, F. R. (1945). Heat activation inducing germination in the spores of thermotolerant and thermophilic aerobic bacteria. J. Bact. 49, 335.

Erikson, D. (1941). Studies on some lake-mud strains of Micromonospora. J. Bact. 41, 277.

Erikson, D. (1947). Differentiation of the vegetative and sporogenous phases of the actinomycetes. The lipid nature of the outer wall of the aerial mycelium. J. gen. Microbiol. $1,39$.

ERIKson, D. (1949). The morphology, cytology and taxonomy of the actinomycetes. Ann. Rev. Microbiol. 3, 23.

Fonsyth, W. G. D. \& Webley, D. M. (1948). The microbiology of composting. II. A study of the aerobic thermophilic bacterial flora developing in grass composts. Proc. Soc. appl. Bact. 3, 34.

Gaughran, E. R. L. (1947). The thermophilic micro-organisms. Bact. Rev. 11, 189.

Gordon, R. E. \& Smith, N. R. (1949). Aerobic spore-forming bacteria capable of growth at high temperatures. J. Bact. 58, 327 .

Gyllenberg, H. (1951). Studies on thermophilic bacteria of the genus Bacillus Cohn. Acta agralia fenn. 73, 1.

HaMpIL, B. (1932). The influence of temperature on the life processes and death of bacteria. Quart. Rev. Biol. 7, 172.

ImSENECKI, A. A. \& SolncevA, L. I. (1945). The growth of aerobic thermophilic bacteria. J. Bact. 49, 539.

JENSEN, H. L. (1930). The genus Micromonospora Ørskov-a little known group of soil micro-organisms. Proc. Linn. Soc., N.S.W. 55, 231.

Morrison, L. E. \& TAnner, F. W. (1924). Studies on thermophilic Bacteria. Bot. Gaz. 77, 177.

Murray, H. C. (1944). Aerobic decomposition of cellulose by thermophilic bacteria. J. Bact. 47, 117.

Pricketr, P. S. (1928). Thermophilic and thermoduric micro-organisms with special respect to species isolated from milk. V. Description of spore-forming types. Tech. Bull. N.Y. St. agric. Exp. Sta. 147.

Robertson, A. H. (1927). The thermal resistance of micro-organisms. Bull. Vt. agric. Exp. Sta. 274.

SchÜтze, H. (1908). Beiträge zur Kenntnis der thermophilen Aktinomyzeten und ihrer Sporenbildung. Arch. Hyg., Berl. 67, 35.

Tsikninsky, P. (1899). Sur les Mucedinées thermophiles. Ann. Inst. Pasteur, 13, 500.

Waksman, S. A., Umbreit, W. W. \& Cordon, T. C. (1939). Thermophilic actinomycetes and fungi in soils and composts. Soil Sci. 47, 37.

Webley, D. M. (1947). The microbiology of composting. I. The behaviour of the aerobic mesophilic bacterial flora of composts and its relation to other changes taking place during composting. Proc. Soc. appl. Bact. 2, 83. 


\section{EXPLANATION OF PLATE}

Fig. 1. Giant colonies of $\boldsymbol{M}$. vulgaris, showing successive rings of growth with diminishing quantities of aerial mycelium, 1 day at $60^{\circ}$ followed by 7 days at $37^{\circ} . \times 1$.

Fig. 2. Colonies of $\boldsymbol{M}$. vulgaris, showing regular development of aerial mycelium, 2 days at $60^{\circ} . \times 1$.

Fig. 3. Short, sporing filaments of Micromonospora vulgaris attached to compost fibre. $\times 960$.

(Received 24 September 1951) 
Journal of General Microbiology, Vol. 6, Nos. 3 and 4
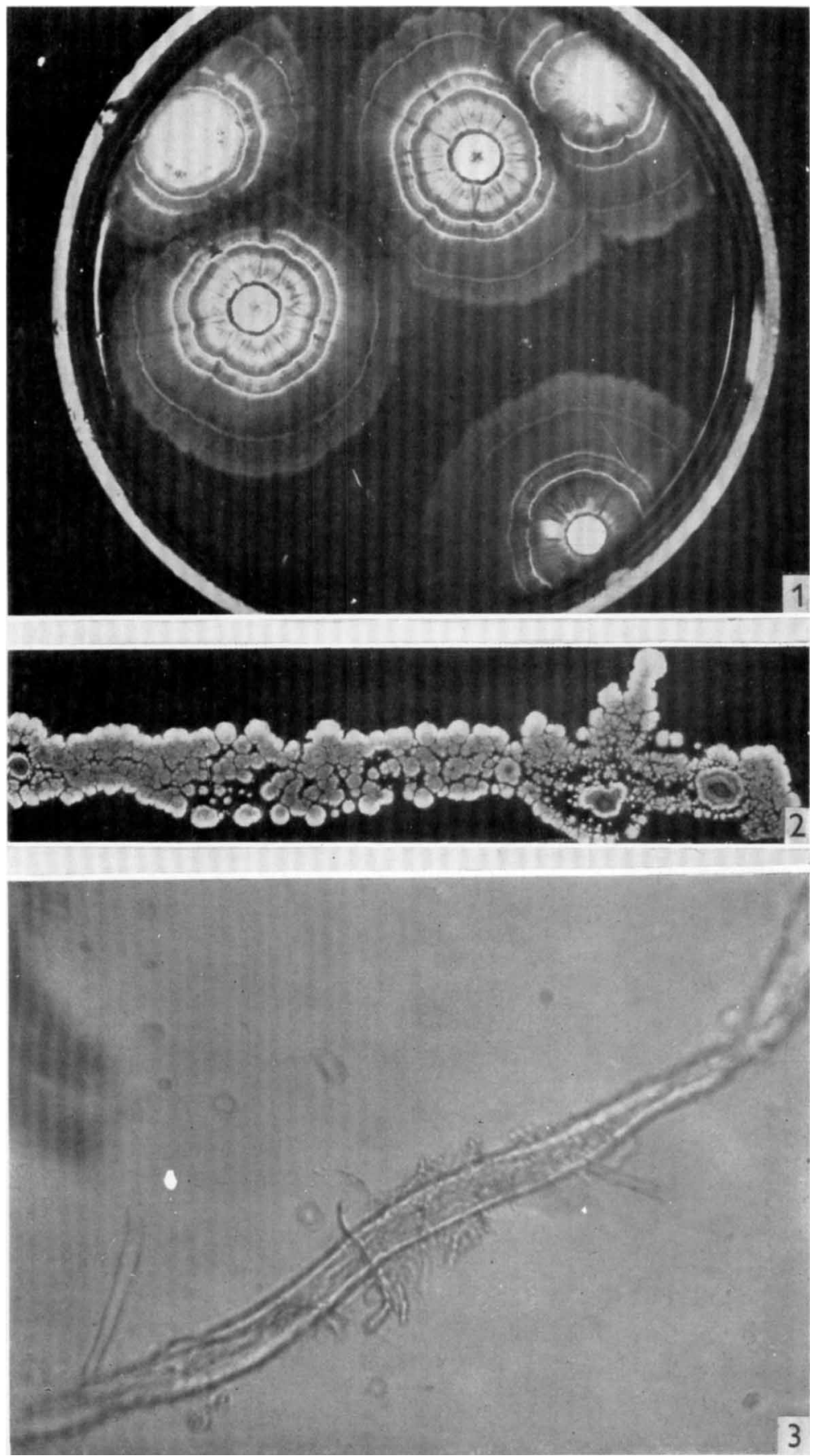

D. Erikson-Properties of a thermophilic actinomycete. Plate 1 